УДК 537.9

\title{
Optimization of the Magnetoelastic Oscillations Amplitudes in the Ferrite Plate
}

\author{
Leonid N. Kotov, ${ }^{*}$ Pavel A. Severin \\ Vladimir V. Vlasov ${ }^{\dagger}$ Dmitriy S. Beznosikov \\ Syktyvkar State University \\ Oktyabrskiy, 55, Syktyvkar, 167001, Russia
}

Received 10.11.2016, received in revised form 12.12.2016, accepted 20.03.2017

The maximum amplitudes of elastic vibrations, depending on the material parameters and parameters of external fields in a normally magnetized anisotropic magnetic plate at its excitation by radio frequency magnetic field were obtained. For this purpose we used the method "simulated annealing". The threedimensional graphics of resonant surfaces of elastic oscillations on the thickness of the plate, on the elastic constants, magnetic damping constant and the magnetoelastic constant in the area of maximum amplitudes found by the simulated annealing algorithm were constructed and explained.

Keywords: magnetoelastic oscillations, ferrite plate, ferromagnetic resonance, simulated annealing. DOI: 10.17516/1997-1397-2017-10-3-330-333.

The paper deals with the use of simulated annealing algorithm to find maxima amplitude of elastic vibrations depending on material parameters and external fields parameters in the normally magnetized magnetic plate excited by an external radio frequency magnetic field. The practical importance of solving of the problem of finding the maximum amplitude of oscillations of elastic plates is that the simulation results can be used to determine the physical characteristics and parameters of external fields, in which the powerful miniature acoustic transducers having magnetostrictive effect can work [1]. Since the experimental search for the maxima of the amplitudes of elastic vibrations is usually hampered by the lack of high-power radio frequency generators and sensitive receivers with low noise, then this calculation allows to narrow down the frequency and amplitude of the of external magnetic fields. Thus the solution of this problem allows to reduce financial expenses and time spent when searching the maxima of the amplitudes of elastic vibrations ferrite plates.

\section{Equations of motion of the magnetization vector in the plate}

Solution of differential equations taking into account the boundary conditions can be reduced to the more general problem of finding the extrema of the objective function, which is a reflection of specific simulated characteristics (for example, the degree of randomness of the excited oscillations, the amplitude of the elastic and magnetic oscillations) in the real number. One of the most effective methods for global optimization method is simulated annealing which is used to solve a large class of problems. Its advantage lies in the fact that even with limited computing resources, it allows us to find one of the extrema, which is close in value to the global extrema [2].

\footnotetext{
*kotovln@syktsu.ru

†vlasovv78@mail.ru

(C) Siberian Federal University. All rights reserved
} 
We consider a complete system of differential equations for the problem of excitation of magnetoelastic vibrations of radio frequency magnetic field in the normally magnetized ferrite plate [3]. The plane-parallel plate with a thickness $d$ having magnetic, elastic and magnetoelastic properties is considered. External DC magnetic field $\vec{H}_{0}$ is applied perpendicular to the plane of the plate and alternating magnetic field vector is applied tangential to the surface of the plate. The problem is solved in a Cartesian coordinate system Oxyz. The plane $O x y$ of the coordinate system coincides with the plane of the plate. The coordinate axes are parallel to the edges of the cube crystallographic cell. The center of the coordinate system $\mathrm{O}$ is in the center of the plate, so that the plate planes coordinates are $\mathrm{z}= \pm \mathrm{d} / 2$.

Assuming that the total energy density of the plate $U$ in the field $\vec{H}=\left\{h_{x}, h_{y}, H_{0}\right\}$ equals the sum of magnetic, elastic and magnetoelastic energy densities, we obtain [4]:

$$
\begin{aligned}
U=-M_{0} h_{x} m_{x}- & M_{0} h_{y} m_{y}-M_{0} H_{0} m_{z}+2 \pi M_{0}^{2} m_{z}^{2}+ \\
& +2 c_{44}\left(u_{x y}^{2}+u_{y z}^{2}+u_{z x}^{2}\right)+2 B_{2}\left(m_{x} m_{y} u_{x y}+m_{y} m_{z} u_{y z}+m_{z} m_{x} u_{z x}\right),
\end{aligned}
$$

Where $\vec{m}=\vec{M} / M_{0}$ is normalized magnetization vector, $M_{0}$ is the saturation magnetization of the magnetic plate, $\mathrm{u}_{i j}$ are components of the strain tensor, $\mathrm{c}_{44}$ is elastic constant and $\mathrm{B}_{2}$ is magnetoelastic coupling constant. The system of the ordinary differential equations describing the magnetoelastic oscillations are obtained in the paper [5].

The system describes the excitation of the transverse elastic oscillations. The initial equations for the system were the Landau-Lifshitz-Gilbert equation and the equations for the elastic displacement vector components $\mathrm{u}_{x, y}[5]$.

The system of the equations was solved numerically by the Runge-Kutta Felberg 7-8 orders method with control the length of the integration step.

\section{Maximizing the value of the elastic displacement}

In solving the problem of finding the maximum magnetization component and the elastic displacement in normally magnetized magnetic plate we taken elasticity constant $c_{44}=$ $7.64 \cdot 10^{11} \mathrm{erg} \cdot \mathrm{cm}^{-3}$ and the density of the plate material $\rho=5.0 \mathrm{~g} \cdot \mathrm{cm}^{-3}$ as fixed input parameters of the model.

Some parameters have changed in the search of the elastic displacement maximum in these ranges: constant magnetoelastic interaction $\mathrm{B}_{2}-10^{6}$ to $10^{8} \mathrm{erg} \cdot \mathrm{cm}^{-3}$; decay of the magnetic and elastic systems constants - $\alpha$ from 0.002 to $0.5, \beta$ from $10^{3}$ to $10^{8} \mathrm{~s}^{-1}$; saturation magnetization $\mathrm{M}_{0}$ from 50 to $600 \mathrm{G}$; the value of the constant field $\mathrm{H}_{0}$ exceeding the saturation field $4 \pi \mathrm{M}_{0}$ on values from 0 to 200 Oe, the frequency of the alternating field $\omega_{0}$ ranged from $10^{8}$ to $3 \cdot 10^{10} \mathrm{~s}^{-1}$; the amplitude of the alternating field components $\mathrm{h}_{0 x}$ varied from 0.05 to 50 Oe.

According to [4], the maximum values of the elastic displacement should take place near the elastic resonance frequency, the value of which was estimated by the formula:

$$
\omega_{\text {res }}=\sqrt{\frac{c_{44}}{\rho}} \cdot \frac{\pi}{d} .
$$

However, when we searched the maximum elastic displacement amplitude $\mathrm{u}_{x}$, we considered this option as a changeable. Constants and parameters of the model corresponding to the found maximum are given in the first string of the Tab. 1. Maximum observed at the highest values of the DC field and the saturation magnetization of the permissible search range. 
Let us consider a three-dimensional resonance of amplitude $U_{x}$ of the components $u_{x}$ on the wafer surface $(z=d / 2)$ from the input parameters, the values of which do not seek to the boundaries of the search ranges (Fig. 1).
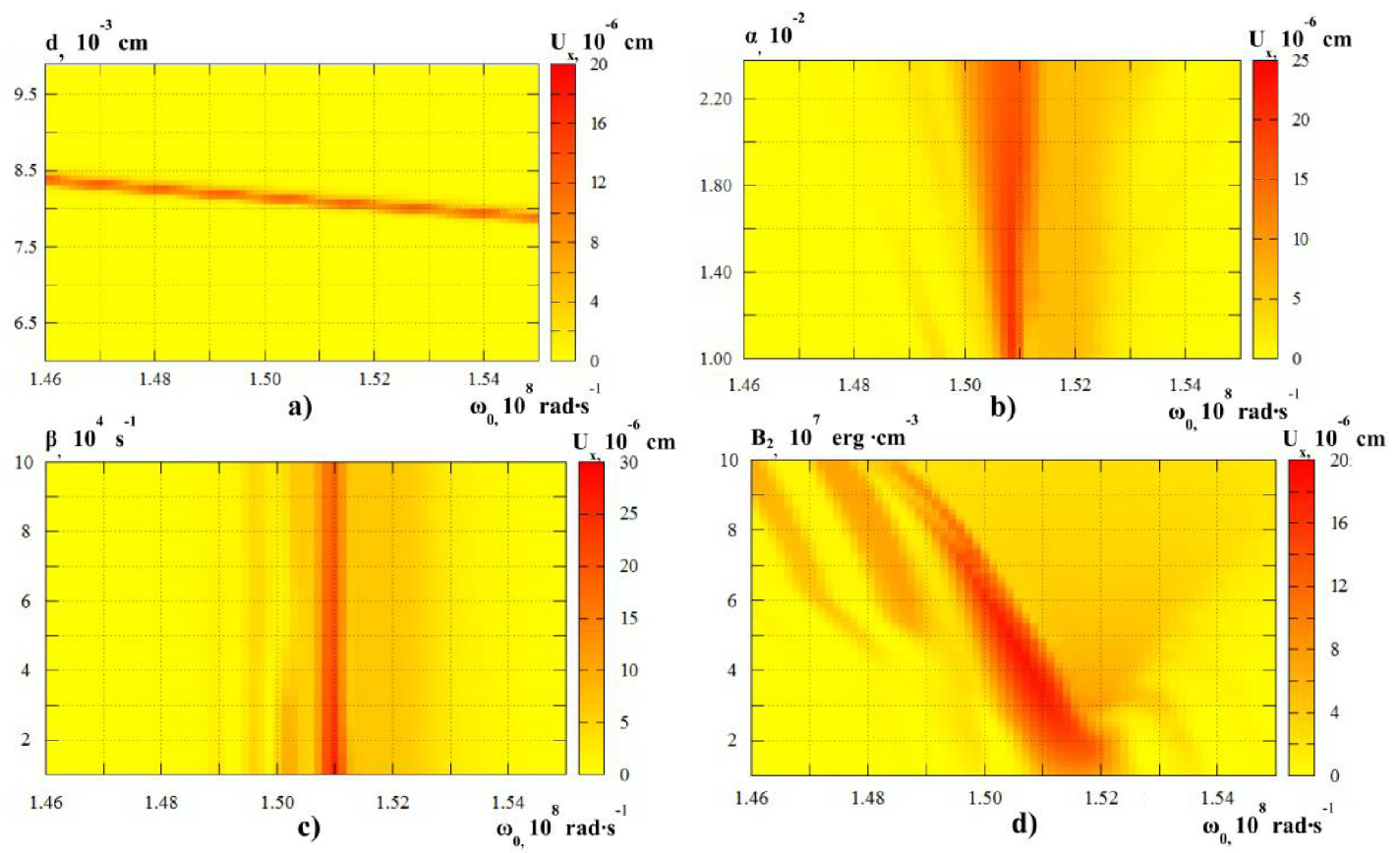

Fig. 1. Dependence $u_{x}$ of the amplitude: a) on the plate thickness; b) on the damping parameter of the magnetic subsystem; c) on the damping parameter of the elastic subsystem; d) on the magnetoelastic interaction constant B2, and on the frequency of the variable field

The position of the maxima in Fig. 1a can be explained by inversely proportional to the frequency dependence of the elastic resonance of the plate thickness, which is defined by the formula (2). Fig. 1b shows the broadening of the main and secondary peaks when the magnetic dissipation parameter $\alpha$ is from 0.01 to 0.026 (about 1.5 times).

On Fig. 1b-1c we can see the resonant surface with the main peak in the center and the secondary on sides. The resonance peaks can be obtained due to the fact that studied oscillating system consists of the interaction of the magnetic and elastic subsystems. The magnetic subsystem is nonlinear and elastic is linear. Additional resonances correspond to the resonance peaks at combination frequencies of the magnetic and elastic subsystems.

For comparability with the existing results we perform simulated annealing based on search with the parameters specified in [3]. The first string of the table 1 shows the amplitude of the elastic displacement of the maxima obtained.

The constants and parameters of the model, in which there is a maximum for the fixed plate thickness $\left(d=6.865 \cdot 10^{-5} \mathrm{~cm}\right)$ is shown in the second string of the Tab. 1 .

Table 1. The constants and parameters for the maximum value of $\boldsymbol{U}_{x}$

\begin{tabular}{|l|l|l|c|l|l|c|c|c|}
\hline $\mathbf{U}_{x, \mathrm{~cm}}$ & $\mathbf{d}, \mathrm{cm}$ & $\alpha$ & $\beta, \mathrm{s}^{-1}$ & $\mathbf{M}_{0}, \mathrm{Gs}$ & $\mathbf{B}_{2}, \mathrm{erg} \cdot \mathrm{cm}^{-3}$ & $\mathbf{h}_{0}$, Oe & $\omega_{0,} \cdot \mathrm{s}^{-1}$ & $\mathbf{H}_{0}$, Oe \\
\hline $1.06 \cdot 10^{-5}$ & $8,1 \cdot 10^{-3}$ & $1.87 \cdot 10^{-2}$ & $4.28 \cdot 10^{4}$ & 599.9 & $3.78 \cdot 10^{7}$ & 49.43 & $1.51 \cdot 10^{8}$ & 7740 \\
\hline $7.5 \cdot 10^{-8}$ & $6.9 \cdot 10^{-5}$ & $2.01 \cdot 10^{-3}$ & 2040 & 289.3 & $5.46 \cdot 10^{7}$ & 19.83 & $1.78 \cdot 10^{10}$ & 4110 \\
\hline
\end{tabular}


It should be noted that this result was obtained by applying simulated annealing without additional information on the range of parameters values, wherein the maximum amplitude of the elastic displacements took place. This indicates the importance of the method of annealing for the study of nonlinear models of excitation of oscillations in multilayer film structures, which is now the urgent task.

\title{
3. Conclusions
}

In this paper we show the possibility of application of simulated annealing to the investigation of nonlinear magnetoelastic systems of large dimension, including relaxation. The values of the material parameters and external fields, corresponding to the maximum elastic displacement for two values of the plate thickness were found based on the analysis of three-dimensional resonant surfaces.

This work was supported by RFBR (grant no. 17-02-01138-a, grant 17-57-150001 НЦНИ-a.).

\section{References}

[1] V.S.Vlasov, A.P.Ivanov, V.G.Shavrov, V.I.Shheglov, The analysis of nonlinear hypersound vibrations excitation of magnetostriction transducer based on connected oscillators model in quadratic approximation, Zhurnal radiojelektroniki, (2014), no. 1, 1-43 (in Russian).

[2] L.Ingber, Adaptive simulated annealing (ASA): lessons learned, Control and Cybernetics, 25(1996), no. 1, 33-54.

[3] V.S.Vlasov, L.N.Kotov, V.G.Shavrov, V.I.Shheglov, Nonlinear excitation of hypersound in the ferrite plate ferromagnetic resonance, Radiotehnika $i$ jelektronika , 54(2009), no. 7, 863-874 (in Russian).

[4] V.S.Vlasov, Relaxation and study of nonlinear dynamics of magnetic and magnetooscillations films and particles, dis. ... kand. fiz.-mat. Nauk, Moscow, 2007 (in Russian).

[5] R.L.Comstock, R.C.LeCraw, Generation of microwave elastic vibrations in a disk by ferromagnetic resonance, J. Appl. Phys., 34(1963), 3022.

\section{Оптимизация амплитуды магнитоупругих колебаний в ферритовой пластине}

\author{
Леонид Н. Котов, Павел А. Северин \\ Владимир В. Власов, Дмитрий С. Безносиков \\ Сыктывкарский государственный университет \\ Октябрьский пр., 55, Сыктывкар, 167001, Россия
}

Найдены максимумы амплитуд упругих колебаний в зависимости от материальных констант и параметров постоянного и переменного магнитных полей в нормально намагниченной анизотропной ферритовой пластине при ее возбуждении радиочастотным магнитным полем. Для решения этой задачи использован алгоритм "имитация отжсиа". Построены и обгяснены трехмерные графики резонансных поверхностей упругих колебаний в зависимости от толщины пластины, упругих констант, параметра магнитной диссипачии и значений констант магнитоупругости в области максимальных амплитуд колебаний.

Ключевые слова: магнитоупругие колебания, ферритовая пластина, ферромагнитный резонанс, метод имитации отжига. 